contains details of examination which would be beyond the scope of many practitioners, as they would not have the necessary equipment, such as an audiometer. It should prove helpful in interpreting results of specialist tests which are forwarded on from the consultant. The diagrams are clear and instructive. The book is well produced, but rather expensive.

\section{THE VITAMINS IN MEDICINE}

By Franklin Bicknell, D.M., M.R.C.P., and FREDERICK PrescotT, M.Sc., Ph.D., F.R.I.C., M.R.C.P. Pp. vii +784 , with 245 illustrations. London: William Heinemann, Ltd. I953. 70s.

The opportunity has been taken of a third edition to revise the text of this book extensively. The book is a comprehensive and completely contemporary account of the subject; 5,500 references are quoted. As is to be expected, the ingenuity of experimenters in devising new types of dietary deficiency in a wide range of animals has produced evidence, not wholly convincing, of new vitamin deficiencies, and new disorders attributable to deficiency of those vitamins already well known. The task of the authors has been to evaluate this enormous mass of new experimental data and attempt to incorporate it into the existing corpus of knowledge. With a few exceptions they have successfully accomplished this task. The book is a valuable addition to any reference library. It is an outstanding piece of scholarship.

\section{V.W.}

\section{The 'Practitioner' Series CLINICAL PSYCHIATRY FOR PRACTITIONERS AND STUDENTS}

By Ian SkotTowe, M.D., M.R.C.P., D.P.M. Pp. $\mathrm{x}+395$. London: Eyre \& Spottiswoode, Ltd. 1953. $36 \mathrm{~s}$.

The author's credo is stated in the preface: 'To know how to examine the patient as a person, what to extrac? from his biography, what to say to him and to his relatives and, above all, to know what should be done to help him and how to set about doing it, are the chief practical aims of psychiatric study. Psychiatry is inherent in general medicine and is subject to the same disciplines. Inference and the interpretation of symptoms should wait cautiously upon meticulous case-taking; the facts will often speak for themselves.'

The text he has written is commendably free from windy speculation on psychopathology and it will be a first-rate book for the senior student and general practitioner. It is not too long $(385$ pages) nor too expensive (36s.), and there are good chapters on psychiatric case-taking and principles of treatment. The nine chapters of clinical description cover the main categories of mental illness, and Dr. Skottowe makes no reference to the psychosomatic or stress disorders. This is as it should be; these disorders belong to the province of general medicine and not psychiatry.
This book fills a place in medical education which has hitherto been vacant; the place for a concise and reliable text of medium length, well furnished with clinical observations.

D.O'N.

\section{PARSON'S DISEASES OF THE EYE}

By Sir Stewart Duke-Elder, K.C.V.O., Ph.D., D.Sc., LL.D., M.D., F.R.C.S., F.A.C.S. 12th Edition. Pp. viii +606 , with 487 illustrations, 22 in colour. London: J. \& A. Churchill Ltd. r954. 42s.

'Parson's Diseases of the Eye' has been a famous textbook of ophthalmology for many years. It has always been said that it contained all the medicine and surgery of ophthalmology sufficient for the diploma in ophthalmology. This is a completely new edition largely rewritten and brought up to date by a new author. He has maintained the high quality and accuracy of the texts. The illustrations in the old editions were always very good, many of these have been retained and in addition many new illustrations have been added and colour reproductions, of which there are a large number, are particularly good. The text is very full and this provides a good basic textbook upon which one can base an ophthalmic library. The chapters on ophthalmic manifestations of general disease are particularly good and should be of great value to the general physician. The chapter on operative technique is brief but contains the essentials of ophthalmic surgery. Particular attention is given to the cataract extraction, its dangers and complications with a dissertation on various methods of extraction. Wisdom has been shown in this, for the cataract extraction is probably the most important operation in the whole of ophthalmic surgery. The book is complete in that it gives the essentials of ophthalmic embryology, anatomy and physiology and optics with all the latest knowledge in these subjectso Errors of refraction are described with the theory of their correction. The chapter on ocular injuries is particularly good and it is very pleasing to see chapters in preventative ophthalmology and the hygiene of vision. This book can now be regarded as an up to date textbook of ophthalmology. In places, however, one feels that older methods of practice have been retained and some are out of place in a book of this quality. For example, in the chapter on glaucoma, leeches are still advocated as part of the treatment, and when removing a subtarsal foreign body after enjoining a student to observe complete asepsis, it is recommended that the foreign body can be brushed off with the finger. These, however, are minor points and do not detract from the quality of the book. To give a survey of the whole subject of this size in so small a book is no easy matter and as a consequence much of the text is rather concentrated and the student may not find it easy reading in parts. The general production of the book is of a very high standard. 